Aksaray University
Journal of Science and Engineering
e-ISSN: 2587-1277
http://dergipark.gov.tr/asujse
http://asujse.aksaray.edu.tr

Research Article

\title{
Analysis of the Failures in Power Transformers
}

\author{
Mehmet Zile* \\ Department of Information Systems and Information Technology, Erdemli Applied Technology and Business \\ School, Mersin University, Turkey \\ -Received Date: Nov 19, $2019 \quad$-Revised Date:Feb 22, $2020 \quad$-Accepted Date:May 05, $2020 \quad$-Published Online: Jun 21, 2020
}

\begin{abstract}
In this study, the failures in Transformer Centers in Mersin Province Erdemli District have been investigated. The causes of the failures have been discussed. It is aimed to create a method for the reasons of possible failures of power transformer. The data have been collected by investigating the faults occurring at the Erdemli Substations. The failure statistics of the 200 power transformer failures that occurred between 2003 and 2019 in the Erdemli district of Mersin province have been examined. Examples of different power transformer failures have been given in fault analysis. The reasons of power transformer failures and the precautions to be taken have been explained.
\end{abstract}

\section{Keywords}

Transformer failures, Power transformers, Failure statistics

\section{INTRODUCTION}

The transformer is the most expensive and integral part of electrical power systems. Power distribution transformers change the high-voltage electricity into a high-current low-voltage state with virtually no energy loss $[1,2]$. Transformers are the complementary elements of many electrically operated devices, and there can be also 500 tons of transformers. Also, power transformers have taken a key role in the transmission and distribution of electricity $[3,4]$. The

\footnotetext{
* Corresponding Author: Mehmet Zile, mehmetzile@mersin.edu.tr
} 
studies in the last fifty years has focused on various magnetic materials and production techniques that can be used in transformers $[5,6]$. Nowadays, there are focused on improving the operating conditions of the power transformer, response in transient situations, possible damage and damage analysis, economics and new designs accordingly. Oiled power transformers have a simple structure with boiler, expansion vessel, bushing, cooling radiators and ventilators containing windings with magnetic circuit $[7,8]$. The conditions for testing the power transformers are increasingly harder. These are high impact voltages, consecutive cycles, the inability to exceed certain levels for ionization and noise, as well as, the determination of the probability of failure by oil analysis, directional cooling, the distribution of the area, special drying $[9,10]$. The main task of power systems is to provide energy in the most economical way, with an acceptable level of reliability and quality to the end user. The reliability of the system depends on the reliability of the elements that make up the system. Preventing malfunctions and operating the transformers under good operating conditions is very important in energy systems. The way to avoid very serious faults in the power transformers and to prevent them from serious financial and technical problems caused by these faults depends on providing a working environment with the tools and equipments equipped with the appropriate technical devices $[10,11]$. In this study, the failures in Transformer Centers in Mersin Province Erdemli District were investigated. The causes of the failures are discussed. The procedure to be used in fault analysis has been introduced in investigation of the power transformer failures used in the electrical transmission systems.

\section{INVESTIGATION OF FAULTS IN TRANSFORMER CENTERS IN ERDEMLI DISTRICT}

The life of the power transformers is 25 to 30 years according to their design. In practice, the life of a power transformer can be extended up to 50 years with appropriate maintenance. Due to the problems related to the manufacturing process in the power transformers, they fail in the first five years of operation or in life periods after twenty years depending on the maintenance and controls applied in the operation. As the transformers age, the risk of failure increases with the weakening of the material. Insulation levels may decrease to a level that cannot withstand faults such as short-circuit faults in the system or transient overvoltages. In the inspections carried out at the substations as seen in Fig. 1, a power transformer without preventive maintenance has exploded due to the deterioration of the insulation paper, and it shows a transformer that has suffered a disaster. 


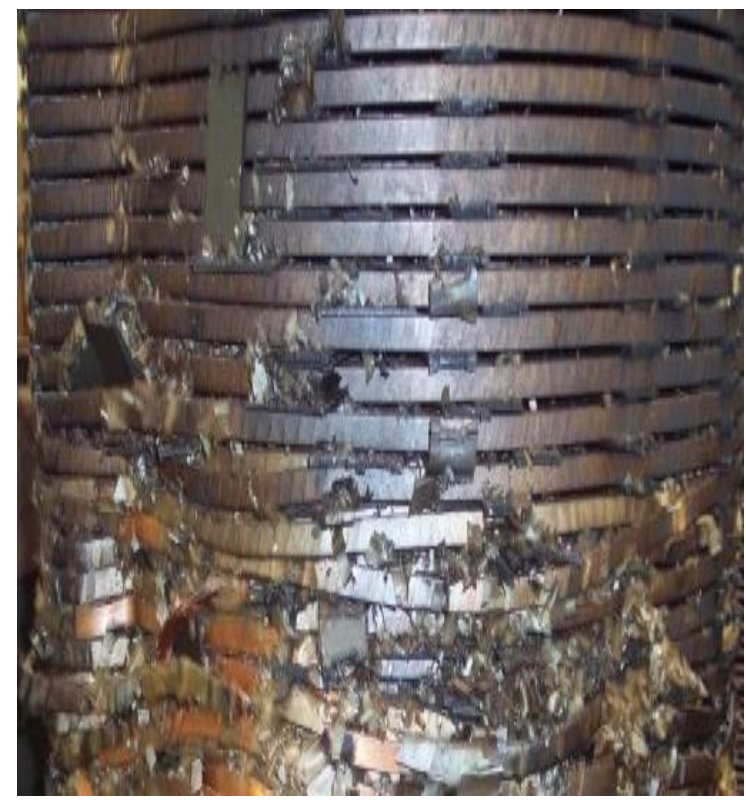

Figure 1. Power transformer exploded without preventive maintenance

The tests and maintenance should be carried out regularly to prevent problems in the power system and ensure the safe operation of the transformers. Despite these, procedures the power transformers have problems. Prepared and preventive measures should be taken in the classification of faults. The data should be collected in a healthy manner. In the investigation of the power transformer failures, the methodology of the most probable causes of any transformer failure detected in the system should be established. Fault and event samples should be provided and the procedure should be determined for routine and uniform data collection. A road map to be followed in fault analysis in the power transformers should be established. Early recognition of the problem in the power transformer slows the development process of the problem. It may be necessary to put together a very comprehensive examination content to examine and identify a fault with all its details. The research studies begin with the suspicion of the operation of the protection relays or the performance of the transformer in case of a transformer failure. The explanatory findings of the fault condition are carefully collected. Fault information should be shared in a healthy way. There are stages of fault analysis preparation, testing, examination and editing of the final report. Information about the fault in the preparation phase is gathered quickly, the document is collected. The external review consists of the internal review and the opening of the power transformer. The history records and information of the power transformer to be examined are collected. Then, the experimental and operating information is obtained. The staff of the operating centre is interviewed, and the records and reports of the history of the transformer are analyzed in detail. Thus, the preliminary report is prepared and revised and the final report is prepared. After the power transformer is energized, the signals belonging to the protection equipment are recorded. In the stage the 
transformer manufacturer must be informed about the defect. Things to do during the preparation phase are the operating manual of the transformer, the transformer test reports, the factory test reports, the field tests, the routine test reports, the single line diagrams of the substation, the protection/secondary protect, the reports related to the past studies or fault conditions, the settings for the protection and measurement systems, is composed of tape measure, protective clothing, field goggles, safety glasses, lenses, searchlight, flashlight, magnet, oil sample bottle and syringe, oxygen meter.In the field review phase, the photographer should take photographs on the defective transformer, make a visual inspection, take necessary notes and obtain the information by applying the necessary tests. Before the power transformer diagnostic tests, it should be noted that the transformer is disconnected from the power system and the auxiliary source points and is properly grounded. In electrical tests, flammable gases must be removed and safety precautions taken. Insulation resistance tests were performed between the winding-winding, the winding-earth, the earth-all the windings, the cor-earth.

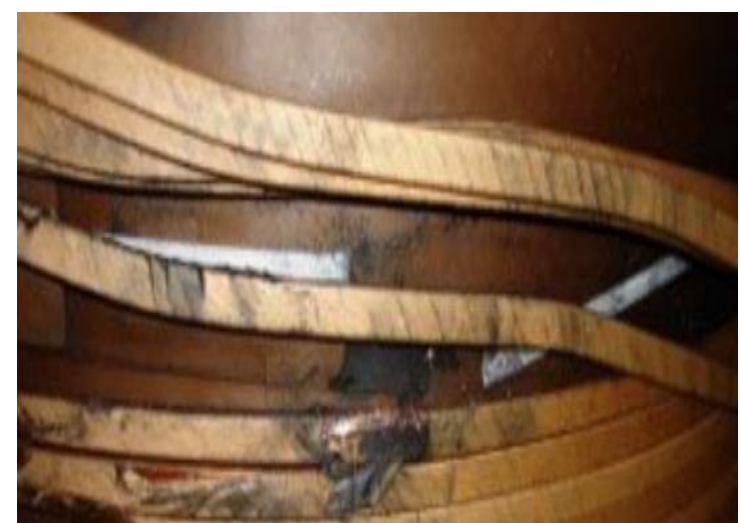

Figure 2. A short-circuit fault in the windings due to the tension and radial forces

The winding ratio was examined and the auxiliary isolation and damage point was determined. Power factor was examined and main isolation was controlled. The winding DC resistance was examined to determine the auxiliary isolation and damage point. Dielectric strength of oil was investigated and the damage point was determined. Warning signals, low voltage impulses, impedance and frequency response analysis were examined and mechanical damage, damage detection and auxiliary isolation control were provided. Induction voltage test is examined and auxiliary isolation control is provided. The winding resistance measurements ensure that a proper connection is made. If there is an open-circuit condition or a high-resistance connection in parallel conductor windings, the detection is provided. This test is applied to determine the mechanical movement of the windings as a result of the low-voltage impulse test, short-circuittest. Partial discharge with induced voltage test is determined in isolation. With the high potential test, the basic pressures of the major insulation are determined. As seen in Fig. 2 in 
the power transformer windings in transformer centers, the transformer coils result in a short circuit due to the tension and radial forces.

White ash, burning housing ashes and solid remains from the burnt bushing are given in Fig. 3 .
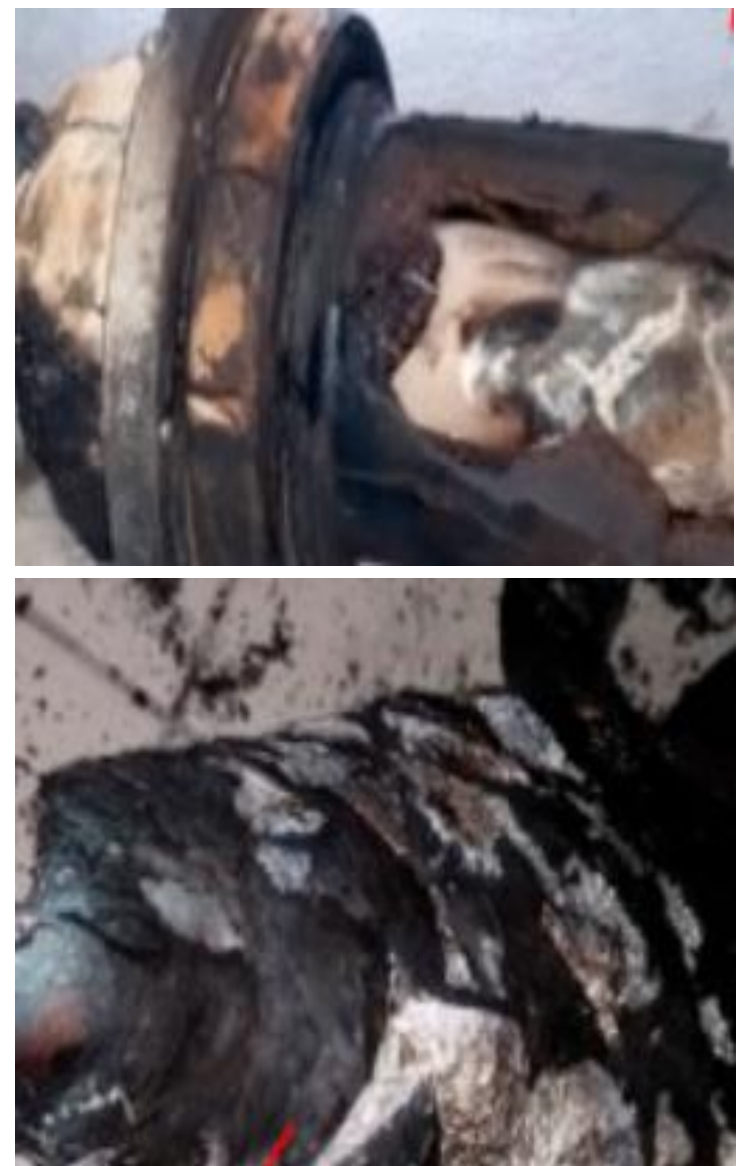

Figure 3. White ash, burning housing ashes and solid remains from the burnt bushing

In the Frequency Response Analysis test, mechanical distortions which could be caused by short circuit faults in windings were determined. In the dielectric strength measurement, the minimum puncture voltage of the liquid insulation was determined between two metal electrodes. Low dielectric strength indicates that the liquid insulation is contaminated or that water, carbon and other impurities are present. The puncture stress of the inner surface of the oil is defined as the bending of the water bubble on the oil film. The increase in surface puncture indicates that the oil is aging. During the electrical arc, corona and high temperature faults occurring in the transformer, the oil molecules are disintegrated and some gases are released. These gases dissolve in oil over time. The insoluble fraction accumulates in the bucholz relay. Hydrogen $\left(\mathrm{H}_{2}\right)$, methane $\left(\mathrm{CH}_{4}\right)$, acetylene $\left(\mathrm{C}_{2} \mathrm{H}_{2}\right)$, ethylene $\left(\mathrm{C}_{2} \mathrm{H}_{4}\right)$, ethane $\left(\mathrm{C}_{2} \mathrm{H}_{6}\right)$ and carbon monoxide $(\mathrm{CO})$, carbon dioxide $\left(\mathrm{CO}_{2}\right)$, nitrogen $\left(\mathrm{N}_{2}\right)$ and oxygen $\left(\mathrm{O}_{2}\right)$ are determined in the gas in the oil. The intensities, ratios and totals of these gases give important findings about transformer failures. After determining the accuracy of the results, other sources of gas 
formation are investigated. For this reason, the gas values are recalculated by removing the previous values from the current gas values and reinterpreting according to the new situation. The internal inspection will determine the fault location as guaranteed and determine the damage size. A low oil level causes contamination to spread, the core and the suffer into the core and the coils. If there is contamination or dirt on the surface of the oil, this pollution must be disposed of. In order to show this situation transformer tank fault is given in Fig. 4.

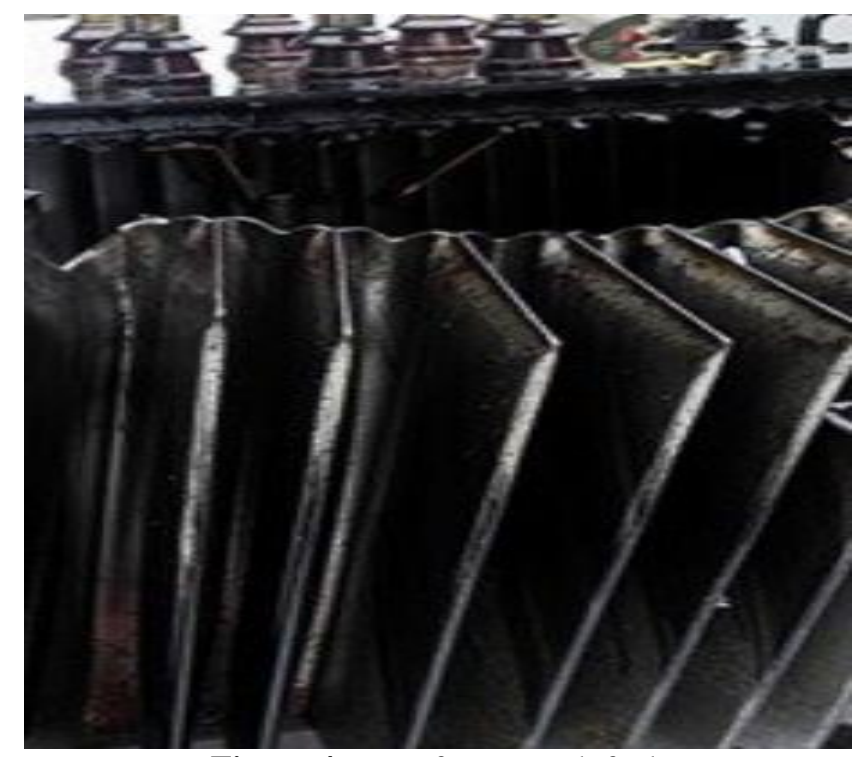

Figure 4. Transformer tank fault

\section{FAILURE STATISTICS IN TRANSFORMER CENTERS OF ERDEMLI DISTRICT}

The failure statistics of the 200 power transformer failures that occurred between 2003 and 2019 in the Erdemli district of Mersin province were examined. Causes of formation of the failure statistics of the power transformers in Erdemli district are obtained as in Fig. 5.

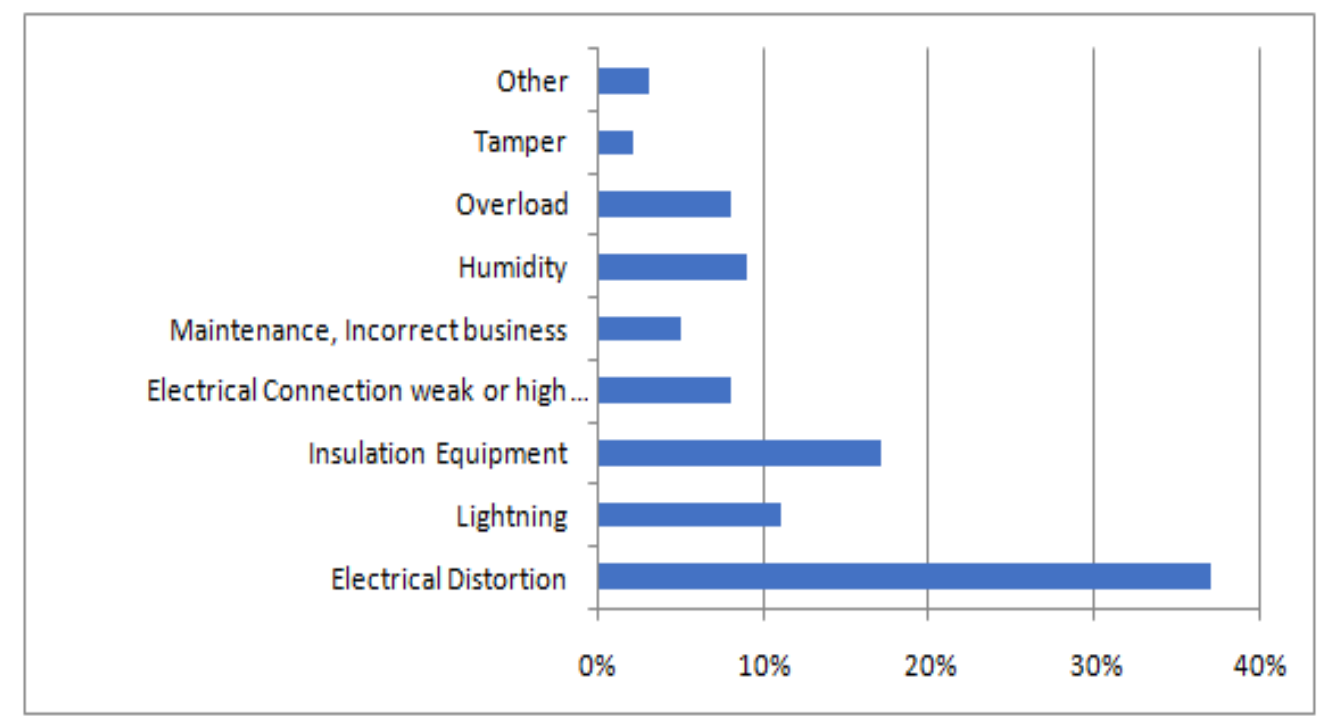

Figure 5. The failure statistics of the power transformers in Erdemli district 
It has been determined that $37 \%$ of the malfunctions in Erdemli District and power substations are caused by electrical disturbances. It was determined that the transformers failed with the lightning strike. In this type of faults, the suitability of the transformer's insulation resistance to the surge arrester puncture voltage should be checked by isolation coordination. In the examinations made; It is understood that lightning, overexcitation, lightning, switching pulse voltage, winding resonance, sipir-sipir short circuit, short circuit of core layers, coil-coil short circuit, partial discharge, isolation puncture, static electricity in the oil and jumps all cause malfunctions. Fault type statistics of the power transformers in Erdemli district are obtained as in Fig. 6.

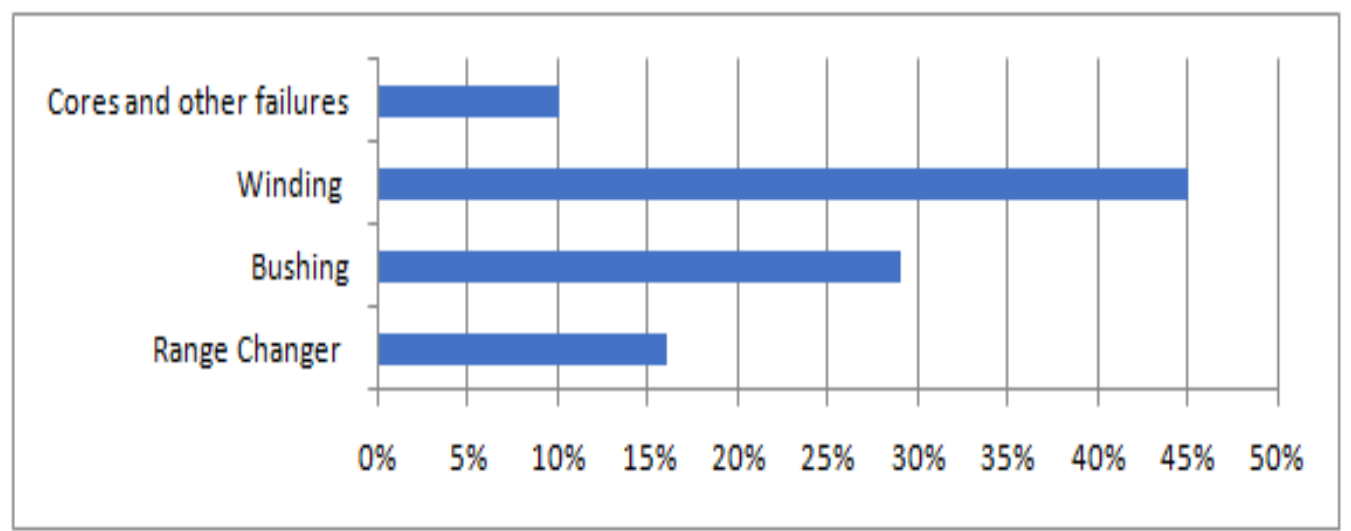

Figure 6. The fault type statistics of the power transformers in Erdemli district

It has been determined that $45 \%$ of the failures in the Erdemli District, power substations are winding failures. These malfunctions; It has been understood that there is short circuit between the windings, short circuit between the windings, winding breaks, winding combustion and cooling systems failures. In the examinations made, it is understood that the reason for this malfunction is due to the fact that power transformers are used in excessive load. At the same time, it has been understood that transformers are not protected against lightning and other atmospheric external effects, there are production defects in the windings used, and deteriorations in the insulating materials used due to excessive moisture.

\section{ANALYSIS AND PREVENTION OF FAULTS IN TRANSFORMER CENTERS OF ERDEMLI DISTRICT}

In order to prevent malfunctions, healthy comments should be made. The collected or obtained information should be systematically analyzed. The information analyzed should be compared with known defects or problems. The hypotheses introduced in the fault analysis should be verified by the information collected and other system equipment. The studies should be 
supported by experimental tests. Faults caused by mechanical factors are caused by failure of the cellulose insulation as a result of deterioration in the physical appearance of wear, swelling and boom. The winding deformation is the one with the effect of electromagnetic forces or during transport. In case of radial effect of the electromagnetic forces in the outward direction, it causes loosening of the conductors. This causes the conductors to be isolated or separated from the insulation. This also causes the conductors to break with elongation, thus exceeding the elasticity limit of the material. With the inward effect of radial forces, it causes mechanical failure in torsion or winding cylinder. The paper insulation in the winding will be ruptured by bending the conductor in the winding, as a result of the contact of the close conductors to each other, a short circuit failure will occur and turn into an electrical fault. In the opposite direction, the forces in the axial direction are affected by the winding center. The forces in the axial direction in the opposite direction cause the holder points to bend or break, or cause the bowed portion to disengage and cut or cut. It causes the winding conductors to shift axially. In the case of internal axial failure, the retaining system is transformed into a mechanical failure due to movement relative to each other in the vertical direction in the opposite direction to the winding. The combination of the axial and radial forces and the covalent compression of the inner windings may occur. The fault occurred when the conductors slipped from the center of the winding and dispersed in the radial space. Sometimes the transformers may have clearance, rupture, wear and poor connection at the beginning of the connection. In this way, the ends or the supporting elements that leave the windings with a weak connection cause a malfunction. Lightning impulse can transform the transformer. In such faults, the insulation resistance of the transformer and the conformity of the surge arrester to the puncture voltage must be checked with insulation coordination. In transformers operated under temporary and continuous over voltage; overpressure on the insulation and overheating of the core cause malfunctions. In case of faults due to the impact voltage and the switching voltage, it is seen that the transformer occurs at the point of the winding connection with the transformer bushing. Partial discharge, also called corona, is due to the design of the poor insulation system, faulty manufacturing, and pollution of the insulation. Partial discharge also produces a low density arc. They damage the insulation and conductors locally. In the case of an operating condition where the transformer insulation oil is at a fairly low temperature, the static load occurs between the oil and the metal parts when the condensed oil moves rapidly. This static load causes severe faults to occur in the transformer tank if the insulation oil exceeds the dielectric capacity. High-frequency system voltages usually generate dielectric stresses in their order close to the connection points of the transformer. In the case of an insulation system fault, the current flows into the live parts in the 
form of a dielectric puncture. he naked conductors are the possible starting points of partial discharge and puncture, especially if there are sharp edges that are deeply irritated or forgot about naked conductors. Insulation materials; moisture, conductive particle contamination or chemical solvents, thermal aging, partial discharges (corona) and mechanical damage or vibration due to weakening due to the task can not. Dielectric failures are actually the result of mechanical, thermal or chemical or factors of the combination. These insulation deficiencies develop in slip or normal operation, sharp edges in the radial cavities used in old transformers cause damage in conductor insulation. Large capacity and small capacity against the soil and the large tension pressures between the winding ends with the end of the line connections occurs. The normal temperature increase by loading the transformer and the working conditions that it will be exposed to under the site conditions reduce the insulation thermally. As a result of the thermal reduction, physical strength will be lost in isolation. Thermal faults occur due to faults caused by the cooling system of the transformer. Long term transformer is overloaded over its design capacity. Blocking of horizontal oil vessel areas and a limited amount of oil in the case of direct contact with the windings creates a thermal failure. The transformer overheats due to the operation of over-excitation. Thermal failures may occur as a result of continuous operation of the transformer under extremely humid conditions. The short circuit in the core holders, the high resistance in the winding connections, the jump etc. electrical faults may ocur because the grounding of the transformer core. Also, there are the fault in auxiliary parts of the power transformers (such as the pumps and fans). Overvoltages caused by atmospheric discharges were found to break the winding heads in the windings. At normal operating voltages, bushing operates normally, but subsequent overvoltages can cause discharges. Such these faults in the bushings are prevented by the addition of the electrical arc horns, and they should be kept away from bushing. When the neutral point of the transformer is not grounded, maneuvering overvoltages may occur higher than overvoltages. Excessive and unbalanced flux due to saturation of the core completes the gap outside the core, thus both the core parts and overheating in the construction will cause. Insulating materials such as paper, lacquer etc. are broken between the core plates. The boiler welds the bolts on the core compression plates. The magnetizing current harmonics cause the winding conductor to overheat due to the skin event and cause damage to the paper insulation. Because of the excess flux completes the circuit from transformer core and construction, some hot spots ocur and burn the transformer oil. The excessive magnetizing current causes the gas to form by heating the coil. The relatively high inductance of transformers and reactors in electrical power systems and the spread capacitances of the transmission systems cause the ferrorezonans conditions to occur easily. The 
ferrorezonans are the result of a breaker or switch being opened and closed, whether the breaker or switch contacts are switched on or switched off at the same time, or if a fuse blows or a line conductor breaks down. Bushing failures are in the form of superficial discharge and insulation perforation. Slight burns on the insulator result from the jumping of bushes made of hard paper or epoxy resin. Such these failures in bushings can be prevented by the addition of the electrical arc horns. The oil level should be checked from time to time on the glazed oil indicator on the top of the bush, and the defective bushing should be replaced with new ones. The electrical discharges are from the tip of the strands to the grounded parts of the transformer. If the loose strands are partially moist, they will form a bridge between the energized parts and the grounded parts and cause a puncture. This condition will be reduced to minimum when fixed by impregnating the filaments with resin. The wind dust and the humidity enter into the transformer during the observation and maintenance, they causes the dry oil to get dirty and to get damp. The strands in the windings absorb from dust and damp oil. As a result, it bridges the electric field and causes the oil to be perforated, and also causes the oil to oxidize.

\section{CONCLUSIONS}

When power transformers fail, they can be cause large production losses and large material losses in enterprises using the electrical energy. The power transformer failures may ocur due to incorrect design, manufacturing defects, poor quality of materials, abnormal operating conditions, unsuitable maintenance and testing techniques, improper operation and nonstandard techniques. In this study, the failures in Transformer Centers in Mersin Province Erdemli District were investigated. The procedure to be used in fault analysis has been introduced in the investigation of the power transformer failures used in the electrical transmission systems. A metedology has been established about the causes of possible failures in the power transformers used in enterprises. A routine and uniform type of data collection procedure has been established to investigate faults of the power transformers used in transmission system. Between 2003 and 2019 years, 200 failures in the Erdemli district of Mersin have been examined and fault statistics have been generated.

\section{REFERENCES}

[1] A. Abu-Siada, S. Islam, A novel on line technique to detect power transformer winding faults, IEEE Trans. Power Delivery, 27(2) (2012) 849-857.

[2] M.S. Ballal, D. M. Ballal, H. M. Suryawanshi, M. K. Mishra, Wing technique: A novel approach for the detection of stator winding inter-turn short circuit and open circuit faults in three phase induction motors, Journal of Power Electronics, 12(1) (2012) 208-214. 
[3] V. Behjat, A. Vahedi, Numerical modelling of transformers interturn faults and characterising the faulty transformer behaviour under various faults and operating conditions, IET Electric Power Applications, 5(5) (2011) 415-431.

[4] V. Behjat, A. Vahedi, An experimental approach for investigating low-level interturn winding faults in power transformers, Electrical Engineering, 95(2) (2013) 135-145.

[5] V. Behjat, A. Vahedi, A. Setayeshmehr, H. Borsi, E. Gockenbach, Sweep frequency response analysis for diagnosis of low level short circuit faults on the windings of power transformers: An experimental study, Journal of Electrical Power and Energy Systems, 42(1) (2012) 78-90.

[6] O. E. Gouda1, A. Z. E. Dein, I. Moukhtar, Turn-to-earth fault modelling of power transformer based on symmetrical components, IET Generation Transmission Distribution, 7(7) (2013) 709716.

[7] Y. C. Kang, B. E. Lee, T. Y. Zheng, Y. H. Kim, P. A. Crossley, Protection, faulted phase and winding identification for the three-winding transformer using the increments of flux linkages, IET Generation Transmission Distribution, 4(9) (2010) 1060-1068.

[8] X. Lei, J. Li, Y. Wang, S. Mi, C. Xiang, Simulative and experimental investigation of transfer function of inter-turn faults in transformer windings, Electric Power Systems Research, 107 (2014) $1-8$.

[9] M. S. Naderi, G. B. Gharehpetian, M. Abedi, T. R. Blackburn, Modelling and detection of transformer internal incipient fault during impulse test, IEEE Trans. Dielectr. Electr. Insul., 15(1) (2008) 284-291.

[10] L. M. R. Oliveira, A. J. M. Cardoso, A permeance based transformer model and its application to winding interturn arcing fault studies, IEEE Trans. Power Del., 25(3) (2010) 1589-1598.

[11] L. M. R. Oliveira, A. J. M. Cardoso, S. M. A. Cruz, Power transformers winding fault diagnosis by the on-load exciting current extended Park's vector approach, Electric Power Systems Research, 81(6) (2011) 1206-1214. 